\title{
Factors affecting customers selection of community pharmacies: The mediating effect of branded
} pharmacies and the moderating effect of demographics

\author{
Dania A. Ghattas ${ }^{\mathrm{a}}$ and Ghaith M. Al-Abdallah ${ }^{\text {* }}$
}

a Applied Science Private University, Jordan

${ }^{b}$ American University of Madaba, Jordan

CHRONICLE ABSTRACT

Article history:

Received: October 9, 2019

Received in revised format: November 252019

Accepted: December 27, 2019

Available online:

December 27, 2019

Keywords:

Pharmacy Selection

Convenience

Physical Environment

Sales Promotions

Qualified Pharmacists

Customer Service

Independent Pharmacy

Chain Pharmacy

Developing Countries

Emerging Economies

Jordan

\begin{abstract}
This research aims to identify and evaluate different factors influencing the customer decision in selecting a community pharmacy in the city of Amman, and study the possible impact of branded pharmacy on the selection process. Five main factors were selected based on the literature review, including convenience, physical environment, sales promotions, qualified and experienced pharmacists and customer service and three main hypotheses and twelve sub-hypotheses were developed. A descriptive analytical methodology, quantitative approach, utilizing survey strategy utilizing questionnaire were used. The population of this research consists of customers who decide to choose a community pharmacy which is estimated at 934.5 thousand households. To collect the primary data, a self-administered questionnaire was prepared based on previous studies; 1070 questionnaires were distributed in different community pharmacies in Amman using convenience sample (pharmacy intercept), 801 filtered and screened questionnaires were sent for statistical analyses. The results reveal that customer service factor had the highest effect on customers' selection of pharmacies, followed by qualified and experienced pharmacists and convenience, respectively. Sales promotions and physical environment have the least impacts on customers' decision. The results also show that there is a partial statistically significant mediation effect of branded pharmacy on the direct relationship between the selected factors and customers' pharmacy selection. The demographic variables have no statistically significant moderating effects on the direct relationship between the selected factors and pharmacy selection. Discussion, managerial implications, and future research recommendations are provided.
\end{abstract}

\section{Introduction}

The Hashemite Kingdom of Jordan is a small developing Arabic country with limited supplies of natural resources. Despite this scarcity of natural resources; it has been able to develop many industries significantly such as pharmaceutical industry. The pharmaceutical sector in general, and community pharmacies field in particular, plays an important role in providing health care services to public, and act as a link between other medicine providers and patients. The Department of Statistics (2016) stated that the number of pharmacies in Jordan has been increased by an average of $25.5 \%$ within the past 4 years. Although there are many regulations by the Jordanian Pharmacists Association (JPA) to control the competition, such as fixed price of medications, the distance between pharmacies and the prevention of any kind of advertising for pharmacies, the competition is still hard due to the rapid increase in the number of pharmacies. In such highly regulated environment, it is important to know how each pharmacy can stand out to attract and retain customers by identifying the factors that customers consider while evaluating and choosing a pharmacy in the presence of many other pharmacies.

* Corresponding author.

E-mail address: ghaith.abdallah@yahoo.com (G. M. Al-Abdallah) 
This research explores and evaluates the factors (the independent variables) affecting customers' selection of pharmacies (the dependent variable) in Amman, the possible mediating effect of branded pharmacy (the mediator variable) on the direct relationship between independent variables and dependent variable, and the possible moderating effect of selected demographics (the moderator variables) on the direct relationship between independent variables and dependent variable.

The research problem can be reflected in the following four main questions:

- What are the main factors affecting customers' selection of pharmacies in Amman?

- Which factor has the most effect on customers' selection of pharmacies in Amman?

- What is the possible mediation effect of branded pharmacy (if any) on the direct relationship between the factors affecting customers' selection and the actual pharmacy selection?

- What is the possible moderation effect (if any) of selected demographics, namely; age, gender, marital status, educational level, monthly income, visits frequency, number of household members, and type of pharmacy on the relationship between the factors affecting customers' selection and the actual pharmacy selection?

\section{Literature Review}

It is important for pharmacies to understand the consumer buying behavior to help them understand in the competition, according to Kotler and Keller (2016) consumer buying behavior "is the study of how individuals, groups, and organizations select, buy, use, and dispose of goods, services, ideas or experiences to satisfy their needs and wants". Thus, it is crucial to understand which factors affect consumer buying behavior the most and why.

\subsection{Factors Affecting Customers Selection of Pharmacies}

Factors affecting the selection of retail stores differ from country to country, and the importance of these factors is still under discussion among academics, researchers and experts in many fields. As emphasized above, the impact of many factors in the selection of retail stores is a controversial topic and need more studies (Al-Abdallah \& Bataineh, 2018; Berisha Qehaja \& Shiroka Pula, 2015). According to Chamhuri and Batt (2009) patients' preferences during pharmacy selection may be closer to their preferences during retail or grocery store selection than their priorities during physician or doctor selection. Hence, the researchers reviewed literature for both of the factors affecting selection of stores while buying fast moving consumer goods and the factors affecting pharmacy and clinic/hospital selection. Based on these studies the following factors were selected: Convenience, Physical Environment, Sales Promotions, Qualified and Experienced Pharmacists and Customer Service (Bahadori et al., 2016; Motawni \& Devendra, 2014; Merks et al., 2014; Eroglu, 2013; Malewski et al, 2015; Abdul Kareem, 2013; Chamhuri and Batt, 2009).

$\mathbf{H}_{\text {a1: }}$ There is a statistically significant direct effect of the selected factors (Convenience, Physical Environment, Sales Promotions, Qualified and Experienced Pharmacists, Customer Service) on the customers' selection of pharmacies in the city of Amman at $(\alpha \leq 0.05)$.

\subsubsection{Convenience}

Convenience is perceived as easily accessible by public transports, wide parking space and consumer friendly environment, which is instrumental attribute in pharmacy retail success, since convenience dimensions have significant importance in retailing and play crucial role in customer store choice. Researchers further identified convenience by different dimensions such as, trading hours, proximity, accessibility, parking and ease of movement. Time and effort, used as dimensions of convenience remain consistent (Abu Bashar \& Saraswat, 2015). In this research, store location, availability of parking facilities and extended operation hours used to define convenience factor.

$\mathbf{H}_{\text {a 1.1: }}$ There is a statistically significant direct effect of convenience on customers' selection of pharmacies in Amman at ( $\alpha$ $\leq 0.05)$.

\subsubsection{Physical Environment}

Store physical environment can be described as all kinds of physical stimulants such as store decoration, product shapes, packages, products display, colors, lightening, ventilation, odors, music, the appearances of sales representatives and their attitudes, other customers, and any other stimuli that may affect the customers experience in some way. Store environment is a good way to gain a competitive advantage for retailers (Alabdallah, 2015). In addition, it's one of the most important factors affecting customers' store selection, as it has positive effect on consumers purchasing attitude and their commitment (Sezgin \& Küçükköylü, 2014).

$\mathbf{H}_{\mathbf{a}}$ 1.2: There is a statistically significant direct effect of physical environment on customers' selection of pharmacies in Amman at $(\alpha \leq 0.05)$. 


\subsubsection{Sales Promotions}

Kotler and Keller (2016) defined sales promotion as "collection of incentive tools, mostly short term, designed to stimulate quicker or greater purchase of particular products or services by consumers". Promotions as a communication tool are more effective than classic media advertising because it can reach customers in the right place and time where purchase decisions remade (Mustafa \& Al-Abdallah, 2020). Promotions are mainly used to attract customers and increase sales through directly influencing individual to take a quick decision and finalize purchasing process (Shamout, 2016). Medicine price was found to have a strong factor affecting repeated purchases and customer loyalty in different markets and countries (Al-Abdallah \& Ahmed, 2018; Brooks \& Simkin, 2012; Goi, 2012) thus it's widely used to attract customers in pharmacies (Lostakova \& Horakova, 2014), however, medicine prices are fixed in most developing countries markets, including Jordan. Pharmacies are banned from offering any sales promotions to control the competition between pharmacies, there are some regulations violation by many pharmacies both independent and chains, and clear manipulation of such regulations without the need to directly provide prices discounts, nevertheless, there will always be a limit to the extent that sales promotion can be used in community pharmacies, which also opens the door for some creativity (Aboumoghli \& Al-Abdallah, 2018).

$\mathbf{H}_{\text {a 1.3: }}$ There is a statistically significant direct effect of sales promotions on customers' selection of pharmacies in Amman at $(\alpha \leq 0.05)$.

\subsubsection{Qualified and Experienced Pharmacists}

Pharmacies are considered as the primary health care services providers through providing advices and counseling about health and medications to patients (Tylee et al., 2007). Pharmacy staff, including pharmacists, must be helpful, courteous and have the willingness to advice the customers directly and in the right way due to high customers' expectations about services in pharmacies (Wang, 2018). Pharmaceutical care is "the responsible provision of drug therapy for the purpose of achieving definite outcomes that improve a patient's quality of life" (Hepler \& Strand cited by Brian et al., 2015). It focuses on patientoriented services and continuous quality improvement in the pharmacy. Pharmaceutical care delivery process consists of seven successive steps that deal with: evaluation of patients' needs, identification of actual and potential drug-related problems, and working with patients and professionals to design, implement and monitor an appropriate treatment plan. In Jordan, the actual application of pharmaceutical care is limited due to the lack of pharmaceutical training and physicians' acceptability to change patient treatment plan following pharmacists' recommendations. Despite the willingness of community pharmacists to implement pharmaceutical care practice; professional training is needed to encourage all health care providers to collaborate and apply these important health care practices (Elayeh, 2017). According to Ayub and Mustafa (2017) single community pharmacies are more willing to use customer relationship management through applying strategies and technologies that used in monitoring and analyzing customer interactions data throughout their lifecycle to improve the relationships with customers, increase customer retention and finally drive more sales (Bataineh et al., 2015).

$\mathbf{H}_{\mathbf{a} \text { 1.4: }}$ There is a statistically significant direct effect of qualified and experienced pharmacists on customers' selection of pharmacies in Amman at $(\alpha \leq 0.05)$.

\subsubsection{Customer Service}

Customer service is defined as an organization's ability to meet the needs and desires of its customers. According to Wreden (2004) professional customer service must include attention, smile, enthusiasm, courteous words, warmth, patience, understanding, sincerity, consideration and appreciation. Although it is hard to develop a customer service plan and it takes effort and time, but if the effort is well spent it will build positive word of mouth and retain customers.

Developing customer service strategy ensures delivering a unique service to customers to buy again from the store due to the intimate touch associated with this customer service approach. Customer service in retail stores must be tailored to meet customers' expectations and ensure their satisfaction (Musasa, 2014).

$\mathbf{H a}_{\text {a 1.5: }}$ There is a statistically significant direct effect of customer service on customers' selection of pharmacies in Amman at $(\alpha \leq 0.05)$.

\subsection{Branded Pharmacies}

According to Loertscher and Schneider (2008) the branded store (or chain store) is a firm consists of two or more branches (stores) which have the same brand name, offer the same merchandise, centrally owned and managed, and usually supplied from central warehouse. Chain stores can be physically differentiated from local stores by standardization of appearance and services, which make it easy for customers to recognize if this store belongs to a particular chain (Alabdallah \& Aborumman, 2012). Standardization tells consumers that they can expect to receive the same type of product and service quality in all stores and in any time while building up a reputation for a certain level of quality is also feasible for local firms (Al-Bourini et al., 2013). It is easy for chain stores to spread the reputation across different local markets through standardization (Al-Abdallah \& Chew, 2020). In developing markets, small pharmacies are being replaced by luxurious, large pharmacy chains managed 
by organized retailers that allow customers to browse through a wide range of products including drugs, body care products, cosmetics and baby care products in a highly comfort and organized environment (Ayub \& Mustafa, 2017). Therefore, these chain pharmacies changed the face of community pharmacy sector, which is highly fragmented nowadays.

$\mathbf{H}_{\mathbf{a} 2}$ : There is a statistically significant mediating effect of branded pharmacy on the direct relationship between the independent variables and the dependent variable at $(\alpha \leq 0.05)$.

\subsection{Personal and Demographic Variables}

According to Ayub and Mustafa (2017) factors affecting consumer behavior can be divided into four main categories: Cultural factors, social factors, cultural factors and psychological factors. However, and due to the nature of products sold in pharmacies, cultural factors, social factors and psychological factors may have low impact on consumer buying behavior in this filed but high effect on other sectors that offer different goods and services (Bataineh et al., 2015). Personal factors in contrast with other demographic factors, including age, occupation, lifecycle stage, self-concept activities, interests, personality and opinions may highly affect customer buying decision within pharmacies. Demographics may moderate the direct relationship between the selected factors and the pharmacy selection since the demographic variables are important determinants affecting the store image and thereby the store choice patronage (Gupta \& Singh, 2012).

According to Keverkidis et al. (2018) young customers, mainly employed with a high educational level and low/high monthly personal income, stated that they do not always visit a single pharmacy and prefer formal relationship with the pharmacy staff. They considered the convenience factors the most important variable in their pharmacy selection process. However, customers who are mainly retired with low to moderate educational level and moderate income appeared to highly value pharmaceutical services. Customers of this segment showed a high level of loyalty to a particular pharmacy, as they were willing to make their purchases from one pharmacy and looking for more personal relationship with the pharmacists. Such evidences indicate the possible effect of demographic variables on the pharmacy selection process by different consumers.

$\mathbf{H}_{\text {a3: }}$ Selected demographic variables have significant moderation effects on the direct relationship between the independent variables and the dependent variable at $\alpha \leq(0.05)$.

\section{Research Methodology}

This research follows a descriptive analytical methodology to achieve its purposes. The descriptive method is used to describe the impact of the independent variable (factors affecting pharmacy selection) on the dependent variable (pharmacy selection). The analytical method is used to explain the possible impact of the independent variables on the dependent variable. Furthermore, this research is utilizing an inductive approach, as the research is concerned with the generation of new knowledge emerging from the data testing starting from specific measurements to broader generalizations and conclusions. Accordingly, a quantitative approach is adopted because it offers estimates of the large population; evaluate their characteristics with statistical accuracy, and measuring their opinions, attitudes and behaviors and how they react toward a specific case. Survey strategy is found to be more suitable to the nature and aims of this research, utilizing a scientifically developed and tested questionnaire as the research instrument.

\subsection{Research Population}

The population of the research consists of individual consumers who make the purchase decision and buy from pharmacies on a periodical basis, on behalf of themselves or their households in Amman, either for personal consumption or for others' consumption. As a matter of fact, these conditions can be found in millions of Jordanian citizens as the majority of Jordanian families generally buy from community pharmacies on regular bases. With no public or general insurance system in Jordan, almost the entire Jordanian population (in households) represents the general population of this study. Consequently, the total population in Jordan is around 10 million according to the Department of Statistics (2018). This number refers to both Jordanians and non-Jordanians who live in Jordan. The non-Jordanian represent almost $30 \%$ of the total population leaving a little over 7 million Jordanian citizens living in Jordan. This population is distributed as follow; around 4.3 million people representing $42 \%$ of Jordan population, forming around 935 thousand households, live in Amman. The remaining $48 \%$ is located as follow; 1.9 million live in Irbid, 1.47 million in Zarqa, 0.59 million in Mafraq, 0.53 million in Balqa, 0.34 million in Karak, 0.25 million in Jerash, 0.20 million in Madaba, 0.20 million in Aqaba, 0.19 million in Ajloun, 0.17 million in Maan and 0.10 million in Tafileh.

\subsection{Research Sample}

Since buying from pharmacies is a periodic process in the Jordanian society and the fact that no complete list of the population of the research can be obtained from any official party in Jordan, the researchers used non-probability sampling technique. Pharmacy intercept sampling, which is a type of convenience sampling, is found to be the most appropriate way to collect the primary data of the research. The researcher limited the sampling frame to the capital city of Amman, since as explained in the section above, $42 \%$ of the Jordanian population lives in Amman, also, Amman residents are a mingle from all Jordanian cities, providing diverse and homogeneous society. According to Gill et al. (2010) in any study with population over 1 million, 
confidence level $95 \%$ and margin of error 3\%, the sample should be 1066 respondents, the researchers aimed at collecting the data from around 1070 respondents since the targeted population included hundreds of thousands of decision makers. 1070 questionnaires were distributed in community pharmacies in the city of Amman and a total of 822 questionnaires were collected with a response rate of $76.8 \%$. After the filtration and screening process, 801 questionnaires were sent to statistical analyses. The sample characteristics are presented in Table 1 as follows.

Table 1

Sample's personal and demographic variables

\begin{tabular}{|c|c|c|c|c|c|c|c|}
\hline Variable & Category & Counts & $\%$ & Variable & Category & Counts & $\%$ \\
\hline \multirow{3}{*}{ Gender } & Males & 367 & 45.8 & \multirow{5}{*}{ Educational level } & High school or less & 122 & 15.2 \\
\hline & Females & 434 & 54.2 & & 2 years Diploma & 151 & 18.9 \\
\hline & Total & 801 & 100 & & Bachelor & 438 & 54.7 \\
\hline \multirow{7}{*}{ Age } & Less than 18 & 30 & 3.7 & & Higher education & 90 & 11.2 \\
\hline & 18 - less than 24 & 87 & 10.9 & & Total & 801 & 100 \\
\hline & 24 - less than 30 & 283 & 35.3 & \multirow{6}{*}{ Monthly income } & Less than $700 \mathrm{JD}$ & 358 & 44.7 \\
\hline & 30 - less than 40 & 255 & 31.8 & & 700 - less than & 270 & 33.7 \\
\hline & 40 - less than 50 & 99 & 12.4 & & 1500 - less than & 106 & 13.2 \\
\hline & 50 and above & 47 & 5.9 & & 2500 - less than & 35 & 4.4 \\
\hline & Total & 801 & 100 & & $3100 \mathrm{JD}$ and more & 32 & 4 \\
\hline \multirow{5}{*}{ Marital status } & Single & 278 & 34.7 & & Total & 801 & 100 \\
\hline & Engaged & 67 & 8.4 & \multirow{6}{*}{ Frequency of visits } & 4 times or more per & 291 & 36.3 \\
\hline & Married & 437 & 54.6 & & $2-3$ times per & 299 & 37.3 \\
\hline & Other & 19 & 2.4 & & Once per month & 84 & 10.5 \\
\hline & Total & 801 & 100 & & Once every two & 56 & 7 \\
\hline \multirow{5}{*}{$\begin{array}{l}\text { Members of } \\
\text { house hold }\end{array}$} & 2 persons or less & 102 & 12.7 & & Once every 3 & 71 & 8.9 \\
\hline & $3-4$ & 314 & 39.2 & & Total & 801 & 100 \\
\hline & $5-6$ & 292 & 36.5 & \multirow{9}{*}{$\begin{array}{l}\text { Types of products } \\
\text { sought }\end{array}$} & Over the counter & 582 & 75.7 \\
\hline & 7 and above & 93 & 11.6 & & Prescribed medica- & 613 & 76.5 \\
\hline & Total & 801 & 100 & & Chronic medica- & 181 & 22.6 \\
\hline \multirow{6}{*}{$\begin{array}{l}\text { Type of } \\
\text { pharmacies you } \\
\text { deal with }\end{array}$} & Single Community pharmacy (spe- & 164 & 20.5 & & Cosmetics & 266 & 33.2 \\
\hline & Chain of pharmacies (specific brand) & 167 & 20.8 & & Food supplements & 217 & 27.1 \\
\hline & Any single community pharmacy & 54 & 6.7 & & Baby care products & 236 & 29.5 \\
\hline & Any chain of pharmacies & 74 & 9.2 & & Others & 9 & 1.1 \\
\hline & I have no preference & 342 & 42.7 & & & & \\
\hline & Total & 801 & 100 & & & & \\
\hline \multirow{6}{*}{$\begin{array}{l}\text { Region of } \\
\text { residence }\end{array}$} & \multicolumn{5}{|c|}{$\begin{array}{l}\text { JabalAlqosor, JabalAljofeh, JabalAltaj, JabalAlnozha, JabalAlashrafiya, JabalAlnadif, AljabalAlakhdar, Down Town, } \\
\text { Alwehdat, Marka, Yajouz, Raghadan, Almahata, Hay Nazzal, Almqabalen, Albnayat, Alhashmi, Almohajeren, Abo } \\
\text { Alanda, Alqwesmeh, Hay Al tafayla. }\end{array}$} & 148 & 18.5 \\
\hline & \multicolumn{5}{|c|}{ Aljwaydeh, Husban, Um Albasaten, MarjAlhamam, Naour, Almowaqar, Aljeza, Alraqem, Sahab. } & 90 & 11.2 \\
\hline & \multicolumn{5}{|c|}{$\begin{array}{l}\text { AlmadinaAlreyadeya, Tla'aAlali, Alrabia, Khalda, JabalAlhussien, Jabal Amman, Um Uthaina, Um Alsummaq, } \\
\text { DeirGhbar, Daboq, Swefieh, Albayader, Alshmesani, Algardens, Abdoun. }\end{array}$} & 302 & 37.7 \\
\hline & \multicolumn{5}{|c|}{ ShafaBadran, Abu Nsair, Tareq, Sweileh, Jubeiha } & 240 & 30 \\
\hline & \multicolumn{5}{|c|}{ Prefer not to say } & 21 & 2.6 \\
\hline & & & & & 801 & 100 & 100 \\
\hline
\end{tabular}

Table 1 presents the sample characteristics where the majority of the sample are females, between the ages of $24-30$ years old, married with a bachelor's degree. The majority of the sample have an income level of less than 700 JD per month and 34 household members, who visit the pharmacy $2-3$ times per month and live in west Amman. The majority of the sample mainly sought prescribed medications from their pharmacies.

\subsection{Primary Data Sources}

A self-administered questionnaire was developed and used to collect primary data. The questionnaire's statements were obtained from previous similar studies with the needed modifications. Five-point Likert scale ranging from strongly agree to strongly disagree was adopted. The questionnaire was developed in English and after all the necessary tests and modifications the final copy was translated into Arabic. The questionnaire contains five main parts. The first part is the cover letter in which the researchers explained the topic of the research and why is it being examined along with clear emphasis on the voluntarily of filling the questionnaire and the right to stop at any time without any questions asked, in addition to the anonymity of the respondents and the confidentiality of collected data. The second part collected data on the independent variables through 30 five-point Likert scale statements. The third part collected data on the dependent variable through 6 statements. The fourth part collected data on the mediator variable through 4 statements, while the fifth and final part collected the demographics characteristics of the sample.

\subsection{Pilot Study}

The research questionnaire was presented to a statistical analysis specialist, a random sample of 25 copies were distributed at random pharmacies in Amman to make sure that the statements are understandable and obvious, the language is simple and clear, the nature of the responses fit the intended meaning, and the questionnaire measured what's supposed to be measuring. Necessary modifications and changes have been taken based on the analyses results. The subsections below explain the process of testing and validation. 


\subsubsection{Face Validity:}

The researchers presented the questionnaire to a panel of 7 experts who are known for their insights. Four of them are academics specialized in the business and marketing filed and 3 of them in the pharmacy commercial field. The views and opinions of the panel were taken into account, the required adjustments were made, and the final questionnaire was sent for further testing.

\subsubsection{Construct Validity}

After establishing the face validity, construct validity was established using correlation coefficients test. The results are presented in Table 2 below.

Table 2

The correlation coefficients between the item and its total for each variable

\begin{tabular}{|c|c|c|c|c|c|c|c|}
\hline & \multicolumn{5}{|c|}{ Independent variable } & \multirow{2}{*}{$\begin{array}{c}\text { Mediator } \\
\text { variable }\end{array}$} & \multirow{2}{*}{$\begin{array}{c}\text { Depended } \\
\text { variable } \\
\text { Pharmacy } \\
\text { Selection }\end{array}$} \\
\hline & Convenience & $\begin{array}{l}\text { Physical Envi- } \\
\text { ronment }\end{array}$ & $\begin{array}{l}\text { Sales Promo- } \\
\text { tions }\end{array}$ & $\begin{array}{c}\text { Qualified Phar- } \\
\text { macists }\end{array}$ & $\begin{array}{l}\text { Customer } \\
\text { Service }\end{array}$ & & \\
\hline 1 & 0.496 & 0.738 & 0.779 & 0.662 & 0.594 & 0.689 & 0.611 \\
\hline 2 & 0.481 & 0.750 & 0.851 & 0.633 & 0.615 & 0.555 & 0.545 \\
\hline 3 & 0.573 & 0.489 & 0.813 & 0.634 & 0.740 & 0.854 & 0.700 \\
\hline 4 & 0.658 & 0.747 & & 0.687 & 0.703 & 0.806 & 0.537 \\
\hline 5 & 0.530 & 0.752 & & 0.624 & 0.635 & & 0.677 \\
\hline 6 & 0.723 & 0.697 & & 0.649 & 0.529 & & 0.797 \\
\hline 7 & 0.725 & 0.686 & & 0.565 & & & \\
\hline
\end{tabular}

Table 2 indicates the person correlation values calculated between each item and the total of the variable (factor) it's assumed to belong to. This kind of correlation expresses the construct validity. It's known that the highest value of correlation that could be reached is (1) so a minimum of $40 \%$ will be considered as acceptable correlation value (i.e. cutoff point of 0.40 ) (Laher, 2010). Inspecting the provided values in the table above, it's clear that all the mentioned correlation values were $>$ 0.40 suggesting good construct validity for each variable (factor) expressed by its related items.

\subsubsection{Reliability Analysis}

In order to establish the questionnaire reliability, the researchers tested the extent of the statements internal consistency, where the cohesion scale is rated by calculating the coefficient Cronbach's alpha. Cronbach's alpha indicates the strength linkage and cohesion between scales statements and sections. In addition, it reflects the grade for persistence (Hair et al., 2010).

Cronbach's alpha testing results are presented in Table 3 as follows.

Table 3

Reliability analysis using Cronbach alpha for internal consistency

\begin{tabular}{|c|c|c|c|}
\hline & Variables & No. of items & Reliability \\
\hline \multirow{6}{*}{ IV } & Convenience & 7 & 0.700 \\
\hline & Physical environment & 7 & 0.785 \\
\hline & Sales promotions & 3 & 0.745 \\
\hline & Qualified and experienced pharmacists & 7 & 0.699 \\
\hline & Customer service & 6 & 0.722 \\
\hline & Factors affecting customers selection & 30 & 0.875 \\
\hline MV & Branded pharmacy & 4 & 0.704 \\
\hline \multirow[t]{2}{*}{ DV } & Pharmacy selection & 6 & 0.700 \\
\hline & Total Questionnaire & 40 & 0.903 \\
\hline
\end{tabular}

Table 3 indicates the results of Cronbach alpha reliability. The values ranged between (0.699) for qualified and experienced pharmacists to (0.875) for the factors affecting customers' selection of pharmacies (IV). These values reflect a good level of reliability given that the maximum value that could be reached is (1.00), a reliability coefficient of 0.60 or higher is considered "acceptable" in the majority social science research situations (Hair et al., 2010) the Cronbach alpha value for the whole questionnaire is (0.903). Accordingly, a conclusion of a satisfactory reliability can be drafted. 


\section{Hypotheses Testing}

Since linear regression is applied to test the hypotheses, the researchers checked for two basic assumptions concerning the application of linear regression; normality of the data distribution of the independent variable and the level of multi co-linearity among the independent variables. The normality of data distribution is described using skewness test, while the multi colinearity is evaluated using the VIF (variance inflation factor), the results are included in Table 4 as follows.

\section{Table 4}

Normality indictor and the VIF test

\begin{tabular}{|c|c|c|}
\hline Variables & Skewness & VIF \\
\hline Convenience & -.243 & 1.489 \\
\hline Physical environment & -.817 & 1.617 \\
\hline Sales promotions & -.816 & 1.371 \\
\hline Qualified and experienced pharmacists & -1.455 & 1.409 \\
\hline Customer service & -.743 & 1.675 \\
\hline Factors total (IV) & -.338 & - \\
\hline Branded pharmacy (MV) & -.390 & - \\
\hline Pharmacy selection (DV) & -.746 & - \\
\hline
\end{tabular}

Table 4 presents the skewness values. The values are considered to be close to the normal distribution if it lies between ( -2 and +2). The mentioned values suggest a closed data distribution to the normal distribution (George \& Mallery, 2010). The VIF results mentioned in the table range between (1.371) for sales promotions and (1.675) for the customer service, values less than (5) are considered to express low co-linearity (i.e. low correlation among the independent variables). Maddala (1992) mentioned that a value of VIF more than 30 is considered to be a big problem, a value more than 10 and less than 30 leads to un trust with the coefficients obtained, a value between 5- 10 reflects a simple issue, while a value less than 5 creates little or no problem at all. Since the two basic assumptions concerning the application of linear regression have been checked, it is safe to apply liner regression to test the hypotheses.

\subsection{Testing the First Main Hypothesis}

The first main hypothesis is tested first through simple regression of the 5 sub-hypotheses it is broken to, then through multiple regression for all the factors combined. The results of the sub-hypotheses testing are presented in the following sections.

\subsubsection{Testing the First Sub Hypothesis of the First Main Hypothesis}

$\mathrm{H}_{\mathrm{a} 1.1}$ : There is a statistically significant direct effect of convenience on customers' selection of pharmacies in Amman at $(\alpha \leq$ $0.05)$.

To test this hypothesis, simple linear regressions was performed. The results are included in Table 5 as follows.

\section{Table 5}

Simple linear regression for testing the impact of convenience on pharmacy selection

\begin{tabular}{crrrrrrr}
\hline Dimension & $\mathrm{R}$ & $\mathrm{R}^{2}$ & $\mathrm{~F}$ & $\mathrm{Sig}(\mathrm{f})$ & $\beta$ & $\mathrm{t}$ & $\mathrm{Sig}(\mathrm{t})$ \\
\hline Convenience & 0.370 & 0.137 & 126.75 & 0.000 & 0.317 & 11.25 & 0.000 \\
\hline
\end{tabular}

Table 5 shows the results of simple linear regression for the impact of convenience on pharmacy selection. The F-value (126.75) is significant because the related sig value $(0.000)$ is less than 0.05 . The beta coefficient reflects the impact value by the independent variable, which is (0.317), and significantly contributes to the dependent variable, as the probability of $t$ statistics value (0.000) is less than (0.05); $t$ statistics test the linearity importance of the beta coefficient obtained for the independent variable. The value of $\mathrm{R}^{2}$ is an important indicator for model fitness known as coefficient of variation, which represents the amount of variation observed in the dependent variable and explained (accounted) by the independent variable(s). As the value of $\mathrm{R}^{2}$ increases the better the model fit is and the stronger explanation of the independent variable. The obtained results indicate that independent viable is accounted for $13.7 \%$ for this model, which is considered a weak effect ( $\mathrm{R}$ is less the 0.4) (Mukaka, 2012).

As a result, the alternative hypothesis is accepted.

\subsubsection{Testing the Second Sub Hypothesis of the First Main Hypothesis}

$\mathrm{H}_{\mathrm{a} 1.2}$ : There is a statistically significant direct effect of physical environment on customers' selection of pharmacies in Amman at $(\alpha \leq 0.05)$.

To test this sub-hypothesis, simple linear regressions was performed. The results are included in Table 6 as follows. 
Table 6

Simple linear regression for testing the impact of physical environment on pharmacy selection

\begin{tabular}{rrrrrrrr}
\hline Dimension & $\mathrm{R}$ & $\mathrm{R}^{2}$ & $\mathrm{~F}$ & $\mathrm{Sig}(\mathrm{f})$ & $\beta$ & $\mathrm{t}$ & $\mathrm{Sig}(\mathrm{t})$ \\
\hline Physical Environment & 0.399 & 0.159 & 151.33 & 0.000 & 0.360 & 12.30 & 0.000 \\
\hline
\end{tabular}

Table 6 shows the results of simple linear regression for the impact of physical environment on pharmacy selection. The $\mathrm{F}$ value (151.33) is significant because the related sig value $(0.000)$ is less than 0.05 . The beta coefficient reflects the impact value by the independent variable, which is $(0.360)$ and significantly contributes to the dependent variable as the probability of $t$ statistics is $(0.000)$ less than 0.05 . The $t$ statistics tests the linearity importance of the beta coefficient obtained for the independent variable. The value of $\mathrm{R}^{2}$ which is an important indicator for model fitness, represents the amount of variation observed in the dependent variable and explained (accounted) by the independent variable. As the value of $\mathrm{R}^{2}$ increases the better the model fit is and the stronger explanation of the independent variable. The obtained results indicate that this dimension is accounted for $15.9 \%$ for this model. Which is considered a weak to moderate effect (R less the 0.4) (Mukaka, 2012).

As a result, the alternative hypothesis is accepted.

\subsubsection{Testing the Third Sub Hypothesis of the First Main Hypothesis}

$\mathrm{H}_{\mathrm{a} 1.3}$ : There is a statistically significant direct effect of sales promotions on customers' selection of pharmacies in Amman at $(\alpha \leq 0.05)$.

To test this hypothesis, simple linear regressions was performed. The results are included in Table 7 as follows.

Table 7

Simple linear regression for testing the impact of sales promotions on pharmacies selection

\begin{tabular}{crrrrrrr}
\hline Dimension & $\mathrm{R}$ & $\mathrm{R}^{2}$ & $\mathrm{~F}$ & $\mathrm{Sig}(\mathrm{f})$ & $\beta$ & $\mathrm{t}$ & $\operatorname{Sig}(\mathrm{t})$ \\
\hline Sales Promotions & 0.331 & 0.110 & 88.58 & 0.000 & 0.191 & 9.92 & 0.000 \\
\hline
\end{tabular}

Table 7 shows the results of simple linear regression for the impact of sales promotions on pharmacy selection. The f value (88.58) is significant because the related sig value $(0.000)$ is less than 0.05 . The beta coefficient reflects the impact value by the independent variable. which is $(0.191)$ and significantly contributes to the dependent variable as the probability of $t$ statistics is $(0.000)$ less than 0.05 . The $t$ statistics tests the linearity importance of the beta coefficient obtained for the independent variable. The value of $\mathrm{R}^{2}$ is an important indicator for model fitness that represents the amount of variation observed in the dependent variable and explained (accounted) by the independent variable. As the value of $\mathrm{R}^{2}$ increases the better the model fit is and the stronger explanation of the independent variable. The obtained results indicate that this dimension is accounted for $11.0 \%$ for this model. Which is weak effect ( $\mathrm{R}$ is less than 0.4) (Mukaka, 2012).

As a result, the alternative hypothesis is accepted.

\subsubsection{Testing the Fourth Sub Hypothesis of the First Main Hypothesis}

$\mathrm{H}_{\mathrm{a} 1.4}$ There is a statistically significant direct effect of qualified and experienced pharmacists on customers' selection of pharmacies in Amman at $(\alpha \leq 0.05)$.

To test this hypothesis simple linear regression was performed. The results are included in Table 8 below.

Table 8

Simple linear regression for testing the impact of qualified and experienced pharmacists on pharmacies selection

\begin{tabular}{crrrrrrrr}
\hline Dimension & $\mathrm{R}$ & $\mathrm{R}^{2}$ & $\mathrm{~F}$ & $\mathrm{Sig}(\mathrm{f})$ & $\beta$ & $\mathrm{t}$ & $\operatorname{Sig}(\mathrm{t})$ \\
\hline Qualified Experienced Pharmacists & 0.492 & 0.242 & 255.48 & 0.000 & 0.622 & 15.98 & 0.000 \\
\hline
\end{tabular}

Table 8 shows the results of simple linear regression for the impact of qualified and experienced pharmacists on pharmacy selection. The f value (255.48) is significant because the related sig value (0.000) is less than 0.05 . The beta coefficient reflects the impact value by the independent variable. Which is 0.62 and significantly contributes to the dependent variable as the probability of $t$ statistics is $(0.000)$ less than 0.05 . The $t$ statistics tests the linearity importance of the beta coefficient obtained for the independent variable. The value of $\mathrm{R}^{2}$ is an important indicator for model fitness that represents the amount of variation observed in the dependent variable and explained (accounted) by the independent variable. As the value of $\mathrm{R}^{2}$ increases the better the model fit is and the stronger explanation of the independent variable. The obtained results indicate that this dimension is accounted for $24.2 \%$ for this model. Which is considered a moderate effect ( $\mathrm{R}$ less than 0.6) (Mukaka, 2012).

As a result, the alternative hypothesis is accepted. 


\subsubsection{Testing the Fifth Sub Hypothesis of the First Main Hypothesis}

$\mathrm{H}_{\mathrm{a} 1.5}$ : There is a statistically significant direct effect of customer service on customers' selection of pharmacies in Amman at $(\alpha \leq 0.05)$.

To test this hypothesis, simple linear regressions was performed. The results are included in Table 9 below.

Table 9

Simple linear regression for testing the impact of customer service on pharmacies selection

\begin{tabular}{crrrrrrr}
\hline Dimension & $\mathrm{R}$ & $\mathrm{R}^{2}$ & $\mathrm{~F}$ & $\mathrm{Sig}(\mathrm{f})$ & $\mathrm{B}$ & $\mathrm{t}$ & $\mathrm{Sig}(\mathrm{t})$ \\
\hline Customer Service & 0.632 & 0.399 & 531.47 & 0.000 & 0.581 & 23.05 & 0.000 \\
\hline
\end{tabular}

Table (9) shows the results of simple linear regression for the impact of customer Service on pharmacy selection. The f value (531.47) is significant because the related sig value $(0.000)$ is less than 0.05 . The beta coefficient reflects the impact value by the independent variable. Which is 0.581 and significantly contributes to the dependent variable as the probability of $t$ statistics is $(0.000)$ less than 0.05 . The $t$ statistics tests the linearity importance of the beta coefficient obtained for the independent variable. The value of $\mathrm{R}^{2}$ is an important indicator for model fitness that represents the amount of variation observed in the dependent variable and explained (accounted) by the independent variable. As the value of $\mathrm{R}^{2}$ increases the better the mode is and the stronger explanation of the independent variable. The obtained results indicate that this dimension is accounted for $39.9 \%$ for this model. Which is considered relatively strong effect ( $\mathrm{R}$ is less than 0.8) (Mukaka, 2012). As a result, the alternative hypothesis is accepted

\subsubsection{Multiple Regression Analyses}

A further investigation of the impact of the factors affecting pharmacy selection was performed by studying the simultaneous effect of all the factors acting together. Such way benefits to differentiate among the factors that significantly contribute to the dependent variable prediction and also to differentiate among the impact values expressed by the beta coefficients. For this purpose, multiple linear regressions were performed. The results are included in the Table 10 below.

Table 10

Multiple linear regression for testing the effect of the selected factors combined on pharmacies selection

\begin{tabular}{lllll}
\hline \multicolumn{1}{c}{ Variables } & \multicolumn{2}{c}{ Coefficients } \\
\cline { 2 - 5 } & & $\beta$ & \multicolumn{2}{c}{ Sig(t) } \\
\hline Convenience & .082 & 3.02 & .003 \\
Physical environment & -.007 & -.22 & .825 & .075 \\
Sales promotions & .031 & 1.78 & .000 \\
Qualified experienced pharmacists & .305 & 7.78 & .000 \\
Customer service & .421 & 13.56 & \\
\hline
\end{tabular}

$\mathrm{R}=0.677 \mathrm{R}-$ Square $=0.459$ Adjusted $\mathrm{R}-$ Square $=0.455 \mathrm{~F}=134.77(0.000)$

Table 10 shows the results of multiple linear regression of all the factors on pharmacy selection. The significance of the relationship between the two variables is concluded by f value (134.77), this value is considered to be significant because the related $\mathrm{p}$ value (0.000) is less than 0.05 . The beta coefficient reflects the impact value by each independent variable (factor). The results reflect the simultaneous impact of all the mentioned factors on the dependent variable. Accordingly, the physical environment and sales promotions showed a non-significant explanation to the variation in the dependent variable. On the other hand, the other three remaining factors contribute to the variation explanation in the dependent variable. Customer service recorded the biggest impact value expressed by the beta coefficient $(0.421)$ followed by the qualified and experienced pharmacists $(0.305)$ then by convenience $(0.082)$. The value of $\mathrm{R}^{2}$ expresses the percentage of variability observed in the dependent variable when using the independent variable to predict it. $\mathrm{R}^{2}$ for this model is $(45.9 \%)$ expressed as a percentage. The adjusted $\mathrm{R}^{2}$ (modified $\mathrm{R}^{2}$ ) is used as a better indicator for the population expected $\mathrm{R}^{2}$, obviously the difference between the two values are so small, indicating that the current sample $\mathrm{R}^{2}$ reflects a good indicator for the population variation.

\subsection{Test the Second Main Hypothesis}

$\mathrm{H}_{\mathrm{a} 2}$ There is a statistically significant mediation effect of branded pharmacy on the direct relationship between the independent variables and the dependent variable at $(\alpha \leq 0.05)$.

To test this hypothesis, Path analysis was used. The results are included in Table 11. Table (11) shows the mediation effect of branded pharmacy on the relationship between the selected factors and pharmacy selection. The magnitude of direct effect of the independent variable on the dependent is expressed by the path weight $(\beta)$ which is 0.567 . The indirect effect caused by the mediator variable is estimated by the mediator's path weights. So the magnitude of the indirect effect is estimated to be 0.124 , as a result, the total effect is expressed by the sum of the direct and indirect effects which equals 0.691 . The sig 
values of the mediator paths are statistically significant, therefore, it can be concluded that branded pharmacy partially mediates the direct relationship between the factors affecting customers' selection of pharmacies in the city of Amman and the pharmacy selection decision.

Table 11

Path analysis for testing the mediation effect of branded pharmacy on the direct relationship between the independent and the dependent variables

\begin{tabular}{lrrrrrr}
\multicolumn{1}{r}{ Path direction } & $\beta$ & $\mathrm{t}$ & Sig $(\mathrm{t})$ & Direct effect & Indirect effect & Total effect \\
\hline Independent on dependent & 0.567 & 14.85 & $0.000^{*}$ & & & $0.691^{*}$ \\
Independent on mediator & 0.918 & 17.15 & $0.000^{*}$ & 0.567 & 0.124 & $0.000^{*}$ \\
\hline Mediator on dependent & 0.135 & 6.28 & & & \\
\hline
\end{tabular}

(*) statistically significant at 0.05 level

As a result, the research alternative hypothesis is partially accepted.

\subsection{Testing the Third Main Hypothesis}

Ha3: Selected demographic variables (Gender, Age, Marital Status, Educational Level, Monthly Income, Pharmacy Visits frequency, Number of house hold members) have a significant moderation effect on the direct relationship between the independent variables and the dependent variable at $\alpha \leq(0.05)$.

To test this hypothesis, multiple linear regressions were performed on each of the demographic variables. The results are included in the Table 12 below.

Table 12

The moderation effect of demographic variables on the relationship between independent and dependent variables

\begin{tabular}{|c|c|c|c|c|c|c|c|c|}
\hline \multirow[b]{2}{*}{ Demographic } & \multicolumn{4}{|c|}{ Model change indicators } & \multicolumn{4}{|c|}{ Coefficients } \\
\hline & $\mathrm{R}^{2}$ & $\mathrm{R}^{2}$ Change & F change & $\operatorname{Sig}(f)$ & Model variables & $\beta$ & $\mathrm{t}$ & $\operatorname{Sig}(t)$ \\
\hline \multirow[t]{3}{*}{ Gender } & \multirow{3}{*}{0.350} & \multirow{3}{*}{0.001} & \multirow{3}{*}{0.82} & \multirow{3}{*}{0.365} & Moderator (MV) & -0.261 & -0.92 & 0.356 \\
\hline & & & & & Independent (IV) & 0.662 & 14.15 & 0.000 \\
\hline & & & & & Moderation effect & 0.061 & 0.90 & 0.906 \\
\hline \multirow[t]{3}{*}{ Age } & \multirow{3}{*}{0.591} & \multirow{3}{*}{0.00001} & \multirow{3}{*}{0.411} & \multirow{3}{*}{0.522} & Moderator (MV) & -0.080 & -0.68 & 0.491 \\
\hline & & & & & Independent (IV) & 0.627 & 6.07 & 0.000 \\
\hline & & & & & Moderation effect & 0.018 & 0.64 & 0.522 \\
\hline \multirow[t]{3}{*}{ Marital Status } & \multirow{3}{*}{0.591} & \multirow{3}{*}{0.00001} & \multirow{3}{*}{0.08} & \multirow{3}{*}{0.767} & Moderator (MV) & 0.039 & 0.25 & 0.799 \\
\hline & & & & & Independent (IV) & 0.715 & 8.03 & 0.000 \\
\hline & & & & & Moderation effect & -0.011 & -0.29 & 0.767 \\
\hline \multirow[t]{3}{*}{ Educational Level } & \multirow{3}{*}{0.593} & \multirow{3}{*}{0.00001} & \multirow{3}{*}{0.29} & \multirow{3}{*}{0.586} & Moderator (MV) & -0.062 & -0.38 & 0.702 \\
\hline & & & & & Independent (IV) & 0.636 & 6.07 & 0.000 \\
\hline & & & & & Moderation effect & 0.021 & 0.038 & 0.586 \\
\hline \multirow[t]{3}{*}{ Monthly Income } & \multirow{3}{*}{0.591} & \multirow{3}{*}{0.00001} & \multirow{3}{*}{0.05} & \multirow{3}{*}{0.821} & Moderator (MV) & -0.039 & -0.28 & 0.778 \\
\hline & & & & & Independent (IV) & 0.676 & 9.62 & 0.000 \\
\hline & & & & & Moderation effect & 0.007 & 0.22 & 0.821 \\
\hline \multirow[t]{3}{*}{ Visits Frequency } & \multirow{3}{*}{0.592} & \multirow{3}{*}{0.00001} & \multirow{3}{*}{0.22} & & Moderator (MV) & -0.067 & -0.58 & 0.561 \\
\hline & & & & 0.635 & Independent (IV) & 0.658 & 9.60 & 0.000 \\
\hline & & & & & Moderation effect & 0.013 & 0.47 & 0.635 \\
\hline Number of household & & & & & Moderator (MV) & -0.207 & -1.20 & 0.228 \\
\hline Members & 0.593 & 0.001 & 1.11 & 0.291 & Independent (IV) & 0.584 & 5.53 & 0.000 \\
\hline & & & & & Moderation effect & 0.043 & 1.05 & 0.291 \\
\hline Type of pharmacies you & & & & & Moderator (MV) & 0.084 & 0.98 & 0.325 \\
\hline deal with & 0.357 & 0.001 & 1.68 & 0.194 & Independent (IV) & 0.776 & 9.91 & 0.000 \\
\hline & & & & & Moderation effect & -0.026 & -1.29 & 0.194 \\
\hline
\end{tabular}

Table 12 shows the direct impact of the demographics as moderators, which is expressed by value of $(\beta)$. The values are not statistically significant as the sig value of $t$ statistics are more than 0.05 in all examined variables, concluding that the direct impact of the moderators is not statistically accepted. Based on the sig values for the effect of moderation interaction, the alternative hypotheses are rejected. 


\section{Discussions and Conclusion}

After identifying the factors affecting customers' pharmacy selection and evaluating the effect of each factor on pharmacy selection, the research concluded that customer service has the highest impact on customers' pharmacy selection among all other examined factors followed by qualified and experienced pharmacists and convenience respectively, whereas the factors sales promotions and physical environment have the lowest impact. In customer service, the most rated item by the research sample is the availability of different payment methods, followed by products availability while the least rated item is offering extra medical services. This maybe because the majority of respondents are between the ages of $24-30$ years old, married with a bachelor degree whose have a busy lifestyle; therefore, they need to be served efficiently and quickly. Providing all the products sought in one pharmacy as one-stop shop, with convenient payment methods and wide insurance coverage are important to the examined population. These results are aligned with Merks et al. (2014) who pointed out that customer service is the first factor which patients consider while choosing a pharmacy in the UK, whereas it came in the second place in Poland (after location of the pharmacy).

According to Merks et al. (2014) qualified and experienced pharmacists is an important factor affecting pharmacy selection in UK, which correspond with this research result as the factor of qualified and experienced pharmacists is rated the second most important factor affecting pharmacy selection in Amman, and this promising result means that Amman residents are aware about the importance of the pharmacists role in improving public health. This could be because of the relatively high educational level of Jordanians, since $85 \%$ of the respondents have diplomas or higher degree. Considering the pharmacy staff experience rather than other factors such as sales promotions activities; reflects high level of awareness, despite the fact that Jordan's economy is burdened due to adverse regional developments, in particular Palestine occupation, and Syria and Iraq crises (World Bank, 2018). Moreover, Wazaify et al. (2008) stated that around 63\% of the population tends to seek advices from the pharmacist rather than doctors in minor diseases in Jordan and more than the half always follow pharmacist directions about over-the-counter medications.

Convenience has been studied extensively in the literature (Bahadori et al, 2016; Merks et al, 2014; Aboumoghli \& Alabdallah, 2012; Chamhuri \& Batt, 2009; Al-Hassan, 2009) and it is the third most important factor affecting pharmacies selection in Amman. The importance of this factor stemmed from the urgent need of pharmacy products in most cases, as the majority of the products sought from pharmacies are prescribed medicines, which normally lead the customers to choose the nearest pharmacy to their home, work, or physician's clinic. However, around 75\% of the respondents visit the pharmacy at least twice per month, so they mostly would select a convenient pharmacy. Pharmacy easy accessibility is the highest item rated by the respondents while availability of valet parking service was the lowest item rated among the convenience dimensions. It should be clear that the idea of valet services are relatively new to the Jordanian society and used to be a service only provided by 5 stars hotels and restaurants (Abu Hammour et al., 2019). Wazaify et al. (2008) showed that only 26\% of respondents visit the same pharmacy because of its convenience location and proximity to their resident or work. Abdul Kareem (2013) found that connivance is not among the factors affecting pharmacy selection in Malaysia. While in Saudi Arabia, Qatar UK, Lebanon, India, and west Australia most customers buy from the same pharmacy mainly due to convenient location and working hours (Kevrekidis et al., 2018; Iskandar et al., 2017; Shaharuddin et al., 2015; El Hajj et al., 2011; Chamhuri \& Batt, 2009; Al-Hassan, 2009).

As mentioned before, Jordan is struggling economically and the populations are considered price sensitive. Despite the fact that nearly $45 \%$ of this research sample has a monthly income less than $700 \mathrm{JD}$, the results show low impact of promotions on customers pharmacy selection, this may be due to the medical nature of the products offered by pharmacies and the fact that choosing the best course of medicine is more important to customers than doing some savings, in addition to the highly restricted regulations imposed by the Jordanian Pharmacists Association concerning medications prices, discounts, offers and any other type of sales promotion whether for independent or chain pharmacies. This is consistent with studies coming from other markets such as Poland and Lebanon, where sales promotions found to have the least impact on customers' pharmacy selection (Merks et al., 2014; Iskandar et al., 2017).

Physical environment has the least importance in selecting pharmacies in Amman, and this can be explained by short pharmacy visits duration, since buying a medication or filling a prescription should not take more than few minutes, thereby the customers may not pay much attention for the details of the environment surrounding them. This is contradicting Wel et al. (2012) results, where store physical characteristics are among the most important factors affecting drug store selection for Malaysian consumers.

According to the current results, the branded pharmacy has a partial mediating effect on the factors affecting customers' pharmacy selection. Although $42 \%$ of the respondents have no preferences towards any pharmacy (whether branded or independent), the pharmacy brand name still has a slight impact on customers while choosing a pharmacy to buy from. Due to the above discussed restrictions on pharmacies marketing, customers cannot differentiate pharmacies easily. This is constant with Abdul Kareem (2013) results, where only weak positive relationship between store brand and pharmacy selection was found. However, Ayub and Mustafa (2017) found that the majority of respondents believed that independent pharmacies need to improve the appearance and increase their professionalism to compete with branded ones, indicating that some customers may prefer the branded pharmacies services over the independent ones. 
In the current study, demographics didn't show any significant moderation effect on the factors affecting pharmacy selection. This could be due to the type of the products sought from pharmacies (mainly medications) and anyone who might need a medication, regardless his age, educational level, marital status, lifestyles, and habits, would think relatively the same. Malewski et al. (2015) found a significant difference between residence region (urban and suburban) regarding customer-pharmacist trust, customer service, and pharmacy accessibility. Moreover, Abu Hammour et al. (2019) stated that patients in Jordan with busy lifestyle showed higher tendency to use the drive-thru service than others, which contradict the results of this research.

\subsection{Recommendations}

In the light of the presented findings, the following recommendations are suggested:

Since the customer service factor has the highest impact on pharmacy selection, pharmacies should focus their efforts on providing superior customer service to create better customer experience leading to their selection by customers in Amman. This can be achieved by offering different and creative medical services, different payment methods, wide range of products and dealing with the majority of the insurance companies operating in the city.

Due to the high effect of pharmaceutical care on customers' pharmacy selection, pharmacies must invest more in their staff through recruiting qualified pharmacists who are willing to provide superior pharmaceutical care, conduct regular training for them in both medical and customer service fields, reward and motivate them by incentives and promotions to support them against the stress of such jobs.

Pharmacy location is also one of the important factors affecting pharmacy selection, choosing a good location is very important issue; the pharmacy must be easily accessible, has convenient operation hours and offers good parking facilities. This might be a recommendation for new pharmacies rather than the already established ones.

On the other hand, pharmacies should not focus their efforts on certain promotional activities such as loyalty cards and advertisements because these factors have low impact on pharmacy selection among the customers who live in Amman.

\subsection{Future Studies}

Any research that can overcome the limitations of this research will be a good future research area. For instance, conducting the same research on a larger sample size to include all cities in Jordan will help the generalization of the results. In addition, the researchers propose conducting the same research while examining other factors that may affect the customers' selection of pharmacies. Also, conducting a similar research on other healthcare sectors (hospitals, clinics, imaging centers and medical laboratories) to compare the results and understand the consumer behavior and attitudes toward the medical sector. Conducting similar study on other services and goods would help create a better understanding of the Jordanian consumer behavior and attitudes in general will be an interesting area for future research as well. Finally, conducting the same research in other regional and international markets to compare the results might enhance our understanding to the factors affecting pharmacy selection in different cultural and social contexts.

\subsection{Limitations}

The researchers faced difficulties in conducting the research on larger number of pharmacies, because many directors (both branded and independent pharmacies) refused to allow the distribution of the questionnaire in their pharmacies. The researchers had to wait in the public street to meet customers leaving such pharmacies. In addition, and due to time and financial constraints, the researchers were unable to expand the research to include other cities in Jordan. This was solved by focusing on Amman which is the largest city and the capital of the country that has almost half of the Jordanian population live in.

\section{Acknowledgment}

The first author is grateful to the Applied Science Private University, Amman, Jordan for the financial support granted for this research project (DRGS-2018-2019).

\section{References}

Aboumoghli, A. \& Al-Abdallah, Gh., (2018), Evaluating the association between corporate entrepreneurship and firm performance. International Journal of Entrepreneurship, 22(4), 1-10.

Abou-Moghli, A. A., \& Al-Abdallah, G. M. (2012). Market analysis and the feasibility of establishing small businesses. European Scientific Journal, 8(9), 94-113.

Abdul Kareem, A. (2013). Determinant Attributes Influencing Retail Pharmacy Selection by Malaysian Consumers. Master's degree Thesis in Business Administration, University of Malaya, Malaysia.

Abu Bashar, A., \& Saraswat, K. K. (2015). Consumer Purchase Intention and Store Attributes: A Study of Delhi \& NCR. International Journal of Marketing \& Financial Management, 3(3), 9-19. 
Abu Hammour, K., Abu Farha, R., Rizik, M., Mukattash, T., Alnan, M., Alkhader, A., ... \& Basheti, I. (2019). Pharmacy drive-thru service in Jordan: assessing customers' awareness, perceptions and factors affecting the use of this service. Journal of Pharmaceutical Health Services Research, 10(1), 141-147.

Al-Abdallah, G. M., \& Abo-Rumman, A. H. (2013). The effect of brand associations on customer loyalty: Empirical study on mobile devices in Jordan. American Academic \& Scholarly Research Journal, 5(1), 122.

Al-Abdallah, G. M., \& Ahmed, R. S. (2018). The impact of corporate social responsibility on customer loyalty in the Qatari telecommunication sector. Journal of Business and Retail Management Research, 13(1), 253-268.

Al-Abdallah, G. M., \& Bataineh, A. Q. (2018). Social networking sites and fashion e-purchasing process. Journal of Business and Retail Management Research, 13(2), 36-49.

Al-Abdallah, Gh. \& Chew, V. (2020) Barriers to Six Sigma implementation in Chinese small and medium steel enterprises, International Journal of Business Excellence 2020.

Al-Hassan, M. I. (2009). A survey on consumer need and opinion about the community pharmacists in Riyadh, Saudi Arabia. Journal of Medical Sciences, 9(1), 36-40.

Ayub, M., \& Mustafa, M. (2017). Consumer buying behavior of retail pharmacy industry with special references to Delhi and NCR. International Journal of Management Studies, 4(2).

Bahadori, M., Teymourzadeh, E., Ravangard, R., Nasiri, A., Raadabadi, M., \& Alimohammadzadeh, K. (2016). Factors contributing towards patient's choice of a hospital clinic from the patients' and managers' perspective. Electronic physician, 8(5), 2378.

Bataineh, A. Q., Al-Abdallah, G. M., Salhab, H. A., \& Shoter, A. M. (2015). The effect of relationship marketing on customer retention in the Jordanian's pharmaceutical sector. International Journal of Business and Management, 10(3), $117-131$.

Berisha Qehaja, A., \& Shiroka Pula, J. (2015). Factors Influencing Store Selection for Supply with Fast-Moving Consumer Goods. Management, 10(4), 315-333.

Brian, O., Chukwuka, E., Chiadichiem, C., Samuel, U., \& Chima, E. (2015). Pharmaceutical care and community pharmacy practice in Nigeria; Grappling with the frontier. European Journal of Pharmaceutical and Medical Research, 2(7), 33-42.

Brooks, N., \& Simkin, L. (2012). Judging marketing mix effectiveness. Marketing Intelligence \& Planning, 30(5), $494-514$.

Chamhuri, N., \& Batt, P. (2009). Factors influencing the consumer's choice of retail store. Stewart Postharvest Review, 5(3), $1-7$.

Department of Statistics (2016). Jordanian Annual Statistical Book. Vol. 67, Amman: Jordan.

Department of Statistics, Directorate of Family and Population Surveys (2018), Estimated Population of the Kingdom by Governorate, Locality Sex and Households, Amman: Jordan. Available at: http://dosweb.dos.gov.jo/DataBank/Population_Estimares/PopulationEstimatesbyLocality.pdf, Retrieved Jan 28/2019.

El Hajj, M. S., Salem, S., \& Mansoor, H. (2011). Public's attitudes towards community pharmacy in Qatar: a pilot study. Patient preference and adherence, 5, 405-422.

Elayeh E., Akour, A., Almadaeen, S., AlQhewii, T., \& Basheti, I. (2017). Practice of pharmaceutical care in community pharmacies in Jordan. Tropical Journal of Pharmaceutical Research, 16(2), 463-470.

Eroglu, E. (2013). Factors affecting consumer preferences for retail industry and retailer selection using analytic hierarchy process. Kafkas University Journal of Economics and Administrative Sciences Faculty, 4(6), 43-57.

Gill, J., \& Johnson, P. (2010). Research Methods for Managers. Fourth Edition, SAGE Publications: London.

Goi, C. L. (2009). A review of marketing mix: 4Ps or more?. International Journal of Marketing Studies, 1(1), 2.

George, D., \& Mallery, M. (2010). SPSS for Windows Step by Step: A Simple Guide and Reference. 17.0 update (10a ed.) Boston: Pearson.

Gupta, R., \& Singh, A. (2012). Customer demographics and choice of retail store for household consumables. Management Convergence, 3(1), 29-46.

Hair, J. F., Black, W. C., Babin, B. J., \& Anderson, R. E. (2010). Multivariate data analysis. Pearson College Division.

Iskandar, K., Hallit, S., Raad, E. B., Droubi, F., Layoun, N., \& Salameh, P. (2017). Community pharmacy in Lebanon: A societal perspective. Pharmacy Practice (Granada), 15(2), 893.

Kevrekidis, D. P., Minarikova, D., Markos, A., Malovecka, I., \& Minarik, P. (2018). Community pharmacy customer segmentation based on factors influencing their selection of pharmacy and over-the-counter medicines. Saudi Pharmaceutical Journal, 26(1), 33-43.

Kotler, P., \& Keller, K. (2016). Marketing Management. Pearson Education, England: United Kingdom.

Loertscher, S., \& Schneider, Y. (2011). Chain stores, consumer mobility, and market structure. Journal of Institutional and Theoretical Economics JITE, 167(2), 236-246.

Lostakova, H., \& Horakova, V. (2014). Usefulness of tools to enhance retention and loyalty in purchasing OTC drugs from the perspective of clients of B\&M Pharmacies. Procedia-Social and Behavioral Sciences, 150, 576-589.

Maddala, G. (1992). Introduction to Econometrics. $2^{\text {nd }}$ ed., Prentice Hall: New Jersey.

Malewski, D. F., Ream, A., \& Gaither, C. A. (2015). Patient satisfaction with community pharmacy: comparing urban and suburban chain-pharmacy populations. Research in Social and Administrative Pharmacy, 11(1), 121-128.

Merks, P., Kaźmierczak, J., Olszewska, A. E., \& Kołtowska-Häggström, M. (2014). Comparison of factors influencing patient choice of community pharmacy in Poland and in the UK, and identification of components of pharmaceutical care. Patient Preference and Adherence, 8, 715.

Motawni, D., \& Devendra, D. (2014). Factors affecting patients' decision in selection of hospital. Management Strategies Journal, 25(3), 5-10. 
Mukaka, M. M. (2012). A guide to appropriate use of correlation coefficient in medical research. Malawi Medical Journal, 24(3), 69-71.

Musasa, T. (2014). Customer Service and Its Impact on Consumer Purchasing Behaviour at Supermarkets in the Greater Area of Ethekwini. Unpublished Thesis, Durban University of Technology, Durban: South Africa.

Mustafa, S. \& Al-Abdallah, Gh. (2020) The evaluation of traditional communication channels and its impact on purchase decision, Management Science Letters, 10, 1-12.

Sezgin, M., \& Küçükköylü, S. (2014). Store's Atmosphere's Importance in Creating Store's Image in Sustainable Management of Store and a Research in Konya (Turkey) City. Journal of Advanced Management Science, 2(3). 186-191.

Shaharuddin, S., Zamaludin, A., Hashim, R., Hadi, M. A., \& Ming, L. C. (2015). Assessing consumer preference using community pharmacy preference evaluation questionnaire (ComPETe): A pilot survey in a Malaysia City. Tropical Journal of Pharmaceutical Research, 14(7), 1299-1303.

Shamout, M. D. (2016). The impact of promotional tools on consumer buying behavior in retail market. International Journal of Business and Social Science, 7(1), 75-85.

Tylee, A., Haller, D. M., Graham, T., Churchill, R., \& Sanci, L. A. (2007). Youth-friendly primary-care services: how are we doing and what more needs to be done?. The Lancet, 369(9572), 1565-1573.

Wang, C., Dang, D., Thanh, N., \& Quang, P. (2018). A study of customers' behavior in the use of pharmaceutical services drugstores in the south of Vietnam. Research in World Economy, 9(1).

Wazaify, M., Al-Bsoul-Younes, A., Abu-Gharbieh, E. and Tahaineh, L. (2008). Societal perspectives on the role of community pharmacists and over-the-counter drugs in Jordan. Pharmacy World Science, 30, 884-889.

Wel, C., Hussin, S., Omar, N., \& Nor, S. (2012). Important determinant of consumers' retail selection in Malaysia. World Review of Business Research, 2(2), 164-175.

World Bank (2018). The World Bank in Jordan. Available at: https://www.worldbank.org/en/country/jordan/overview, Retrieved December 12/2018.

Wreden, N. (2004), How to Recover Lost Customers, Available at: http://www.smartbiz.com/article/articleview/112/1/7/, Retrieved January 5/2018.

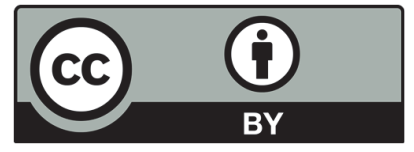

(C) 2020 by the authors; licensee Growing Science, Canada. This is an open access article distributed under the terms and conditions of the Creative Commons Attribution (CC-BY) license (http://creativecommons.org/licenses/by/4.0/). 